\title{
Postgraduate Courses in Pharmaceutical Medicine in Italy
}

\author{
Domenico Criscuolo* \\ Genovax, Colleretto Giacosa, Italy
}

Italy has a significant tradition of excellence in the area of clinical trials (CTRs): important achievements in the clinical development of rifampicin and adriamycin, the two most famous drugs discovered in the research laboratories of two Italian pharmaceutical companies, paved the way to the establishment of a culture of clinical development, mainly in the areas of antimicrobials and oncology. Despite the fact that now the Italian market of pharmaceuticals is largely dominated by multinational companies with headquarters outside Italy, the contribution of Italian studies to the clinical development of new drugs is still significant. Indeed, it largely exceeds the percentage of Italian inhabitants versus the ones living in the remaining EU countries, as Italy has about $12 \%$ of EU population, but has a $17 \%$ share of the EU CTRs. Education in Pharmaceutical Medicine is now a

Edited by:

Sandor Kerpel-Fronius, Semmelweis University, Hungary

Reviewed by:

Dominique J. Dubois,

Free University of

Brussels, Belgium Rolf Bass,

Retired from BfArM, Germany

Romaldas Maciulaitis,

Lithuanian University of Health Sciences, Lithuania

*Correspondence: Domenico Criscuolo dcriscuolo@genovax.it

Specialty section: This article was submitted to

Regulatory Science,

a section of the journal

Frontiers in Medicine

Received: 28 February 2017

Accepted: 30 May 2017

Published: 16 June 2017

Citation:

Criscuolo D (2017) Postgraduate

Courses in Pharmaceutical

Medicine in Italy.

Front. Med. 4:79.

doi: 10.3389/fmed.2017.00079 must for all professionals interested to work either in pharma companies or in contract research organizations: several Italian universities are offering high quality courses, and in the last 10 years, more than 1,200 professionals received a postgraduate education in pharmaceutical medicine. This result places Italy on top of countries concerned about the professional education of people involved in drug development and will represent an asset for a larger involvement of Italian clinical sites in the global process of clinical research.

Keywords: postgraduate education, Italy, pharmaceutical medicine, clinical trials, drug development

\section{INTRODUCTION}

The Italian pharmaceutical industry had a boom in the post World War 2 era (1), boosted by the desire for a better control of diseases and also by the lack of a law about patent protection (Figure 1). In this dynamic scenario, Italian chemists and pharmacologists had the opportunity to establish various research groups, and some of them achieved very important results. In particular, the research groups in Lepetit and in Farmitalia, two large companies based in the area of Milan, discovered rifampin and adriamycin. The clinical development of these two key medicines, always present in the WHO list of essential drugs, created a scientific and managerial environment, which formed the basis of a reputation of excellence of the Italian clinical research $(2,3)$.

In the following decades, the lack of political support and also a short vision of Italian industrial families stimulated several foreign multinational companies to acquire Italian pharmaceutical companies: from 1980 to 2000, the scenario drastically changed, with foreign multinational companies conquering about $80 \%$ of the Italian market (Figure 1). However, the positive image of excellence in clinical research was safeguarded, and Italian professionals continued to keep in good shape the value of clinical studies performed in Italian trial sites. 


\section{n companies}

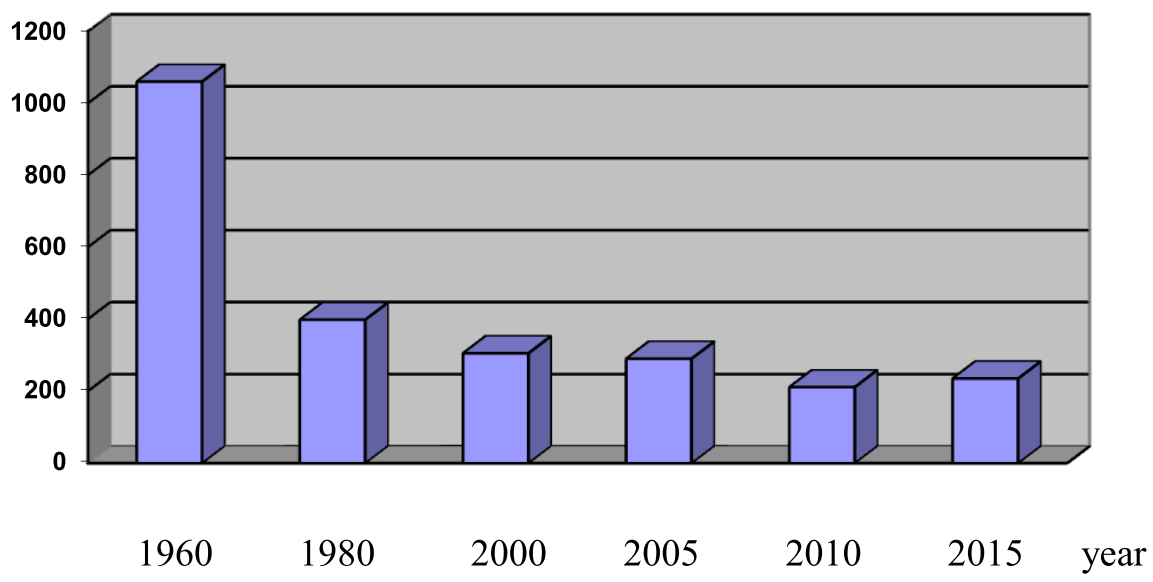

FIGURE 1 | Number of pharmaceutical companies active in Italy from 1960 to 2015 (from Farmindustria).

Indeed, the number of clinical trials (CTRs) performed in Italy from the year 2000 onward, recorded in a dedicated page of the website of the Italian Medicines Agency (AIFA) (4), moved from 557 to a peak of 880 in the year 2008: since then, the global crisis affecting the number of clinical studies had some consequences also in Italy, which, however, continues to keep a good number of CTRs (Table 1). The comparison with the other countries of the European Union is even more encouraging: Italy has always got a share of the total number of CTRs ranging from $16.4 \%$ (year 2011) to $18.2 \%$ (year 2014), and this share is stable above 17\% (Table 2). This is a significant result, having in mind that the Italian population is made of about 60.5 million inhabitants and represents approximately $11.8 \%$ of the population of the 28 countries of the European Union, which in the year 2015 was about 510 million people. Of course, this is a generic indicator, which, however, is suggestive of an interesting trend.

Quality in clinical research is a must: this process, which started in the 1980s with the implementation of the Good Clinical Practice methodology, is being continuously updated with revisions and amendments. Education in Pharmaceutical Medicine started to get interest from professionals in clinical research, who identified the need for dedicated university master courses devoted to all areas of medicines development: and the first master courses were established in Europe and in Italy at the end of the 1980s. Initially, these courses were attended by a minority of professionals, only stimulated by the personal wish to get a more comprehensive education in Pharmaceutical Medicine.

As Italy is concerned, the turning point of students' participation to master courses in Pharmaceutical Medicine was in the year 2008. The Italian Medicines Agency, having in mind the relevant number of CTRs performed in the country (Table 1), issued a decree entitled "Definition of the minimum requirements, which Contract Research Organizations (CROs) shall satisfy in order to work within CTRs on medicinal products" (5). This decree imposed a significant mandatory training for all professionals wishing to work as clinical monitors and related tasks,
TABLE 1 | Number of clinical trials (CTRs) approved in Italy from 2000 to 2015.

\begin{tabular}{lc}
\hline Year & Number of approved CTRs \\
\hline 2000 & 557 \\
2001 & 605 \\
2002 & 560 \\
2003 & 568 \\
2004 & 624 \\
2005 & 664 \\
2006 & 778 \\
2007 & 796 \\
2008 & 880 \\
2009 & 761 \\
2010 & 670 \\
2011 & 676 \\
2012 & 697 \\
2013 & 583 \\
2014 & 592 \\
2015 & 672 \\
\hline
\end{tabular}

TABLE 2 | Number of clinical trials approved in EU countries and in Italy from 2011 to 2015.

\begin{tabular}{cccc}
\hline Year & $\begin{array}{c}\boldsymbol{n} \text { trials approved } \\
\text { in EU countries }\end{array}$ & $\begin{array}{c}\boldsymbol{n} \text { trials approved } \\
\text { in Italy }\end{array}$ & $\begin{array}{c}\text { Percentage } \\
\text { Italy/EU }\end{array}$ \\
\hline 2011 & 4,127 & 676 & 16.4 \\
2012 & 3,943 & 697 & 17.7 \\
2013 & 3,383 & 583 & 17.2 \\
2014 & 3,249 & 592 & 18.2 \\
2015 & 3,918 & 672 & 17.2 \\
\hline
\end{tabular}

lasting for 6 months: however, this training could be avoided in the event the clinical monitor had got a University master title in Pharmaceutical Medicine. This law was a tremendous boost to master courses: in fact, from the year 2008 onward, the majority of pharmaceutical companies and practically all CROs, whenever looking for new hires, require the master title, which 
TABLE 3 | Master courses in pharmaceutical medicine and related areas, active in Italy, and number of professionals who got the master title.

aCatholic University - Rome (PharmaTrain Center of Excellence)

$n=300$

aBicocca University - Milano (PharmaTrain Center of Excellence)

$n=200$

aState University "La Sapienza" - Rome

aState University-Pisa

aState University - Milano

aState University "Tor Vergata" - Rome

aState University -Florence

aState University - Camerino

'Second University - Naples

'State University-Pavia

bState University - Catania

'State University - Verona

'State University-Novara

Learning outcomes are related to the following

apharmaceutical medicine.

${ }^{b}$ Drug safety.

"Market access.

will guarantee to have not only well trained professionals but also people ready to be active in their jobs. And in fact not only University masters established before the year 2008 had a significant increase in applications but several new master courses were established all over Italy, in order to satisfy an increasing demand of postgraduate courses in Pharmaceutical Medicine (Table 3).

Some years ago, in an evaluation of Pharmaceutical Medicine in Italy (6), I estimated that about 3,000 professionals were working in Italy on jobs closely related to all areas of medicines research and development: I presume that this number has now increased, mainly driven by the large number of new hires from CROs, possibly reaching the level of 5,000 people. It is noteworthy to underline that we have today in Italy about $25 \%$ of professionals devoted to drug development who have a postgraduate education in Pharmaceutical Medicine. It is my solid opinion that Italy is now the country with the largest number of professionals in clinical research with a postgraduate title: this result will certainly

\section{REFERENCES}

1. Farmindustria. Indicatori farmaceutici. (2016). Available from: http://www. farmindustria.it

2. Oppolzer W, Prelog V, Sensi P. The composition of rifamycin B and related rifamycins. Experientia (1964) 20:336-9. doi:10.1007/BF02171084

3. Monfardini S, Bonadonna G, Di Pietro S, Guindani A, Fossati-Bellani F, De Lena M. Clinical trials with adriamycin in leukemia and solid tumors. Tumori (1969) 55:197-216.

4. AIFA. Italian national observatory on clinical trials on medicines (OsSC). $16^{\text {th }}$ National Report on Clinical Trials on Medicinal Products. AIFA Rome (2016). Available from: http://www.aifa.gov.it

5. Italian Ministry of Health. Definition of the Minimum Requirements Which Contract Research Organizations (CRO) Shall Satisfy in Order to Work within Clinical Trials on Medicinal Products (Vol. 279). Rome: Gazzetta Ufficiale (2008).

6. Criscuolo D. Pharmaceutical medicine in Italy. Pharm Med (2010) 24:15-9. doi:10.1007/BF03256794

7. The PharmaTrain Federation (2014). Available from: http://www.pharmatrain.eu

8. The International Federation of Associations of Pharmaceutical Physicians \& Pharmaceutical Medicine (2014). Available from: http://www.ifapp.org improve the quality of clinical studies performed in Italy, and possibly attract an even larger number of international trials.

Finally, let me add that the objective for a better quality is being continuously upgraded. So, what is the current scenario offering? The new target is the title of Specialist in Medicines Development (SMD), a joint program implemented by the PharmaTrain Federation (PTF) (7) and the International Federation of Associations of Pharmaceutical Physicians and Pharmaceutical Medicine (IFAPP) (8). These two federations have collaborated since the year 2009 in the IMI funded program called "PharmaTrain" (9), which aimed at harmonizing the programs of European master courses in Pharmaceutical Medicine. The Pharmatrain program achieved a good success, and from 2009 to 2014 was able to create a network of 15 master courses run in European countries and adopting the same syllabus. This innovative idea of harmonization is now further supported by the PTF, which has in addition launched the SMD project. This program is being offered to all professionals with a master title, and is a 2-year supervision on the job, managed by a tutor, who is responsible to make sure that the applicant becomes expert in the seven domains of Pharmaceutical Medicine (10).

\section{CONCLUSION}

Pharmaceutical Medicine is a profession, which requires a regular update of competencies, as drug development opens continuously new frontiers: postgraduate master courses are now widely available, with a harmonized syllabus, which guarantees a similar education on a global basis. The SMD program, which is being initially implemented in Italy and in Japan, starting in 2017, represents an additional step of the quality ladder: a must for all professionals in Pharmaceutical Medicine.

\section{AUTHOR CONTRIBUTIONS}

The author confirms being the sole contributor of this work and approved it for publication.

9. IMI Call Topics. Topic 16: Pharmaceutical Medicine Training Programme. Version 24. Bruxelles (2008). p. 86-90.

10. Silva H, Stonier P, Buhler F, Deslypere JP, Criscuolo D, Nell G, et al. Core competencies for pharmaceutical physicians and drug development scientists. Front Pharmacol (2013) 4:105. doi:10.3389/fphar.2013. 00105

Conflict of Interest Statement: The author declares that the research was conducted in the absence of any commercial or financial relationships that could be construed as a potential conflict of interest.

The reviewer, DD, and handling editor declared a past co-authorship with the author, but the handling editor ensured that the process met the standards of a fair and objective review.

Copyright (c) 2017 Criscuolo. This is an open-access article distributed under the terms of the Creative Commons Attribution License (CC BY). The use, distribution or reproduction in other forums is permitted, provided the original author(s) or licensor are credited and that the original publication in this journal is cited, in accordance with accepted academic practice. No use, distribution or reproduction is permitted which does not comply with these terms. 